\title{
Do not Tell me How to Talk to Men! A Critical Discourse Analysis on Matthew Hussey's Advice on "How to Charm him with your Texts"
}

\author{
Valeria Márquez Arellano \\ University of Guanajuato, Division of Social Sciences and Humanities, MEXICO
}

Received: 27 May 2020 • Accepted: 19 July 2020 • Published Online: 9 September 2020

\begin{abstract}
Gender in discourse and feminist ideologies have been more examined in different fields. Regarding the area of Applied Linguistics, there has been more attention to how men and women are represented linguistically, more specifically in feminist studies. The following article examines the chapter "How to charm him with your texts" of a book that provides women with advice on "how to get the man". I provide a feminist critical discourse analysis (Lazar, 2007) with the support of previous studies on critical discourse analysis (Fairclough, 2010). This article sheds light on some women categorization made by the author of the book and from a feminist ideology perspective.
\end{abstract}

Keywords: critical discourse analysis, feminist critical discourse analysis, gender in discourse, feminist ideologies.

\section{Introduction}

This article is a critical discourse analysis of a chapter in Matthew Hussey's book "how to talk to men". To begin with, a brief overview will be presented to give context about the book and the author. Then, the theoretical framework used for this analysis will be discussed as well as some terms that need to be mentioned to understand the analysis of the chapter. Therefore, an analysis of the chapter will be presented. Finally, a conclusion, closing thoughts, and suggestions for further research will be presented.

\subsection{About Matthew Hussey and his work}

Matthew Hussey works as a love life coach. He has a YouTube channel where he uploads different videos to help women with their relationships. Hussey is also a writer and his books as well as his podcasts, videos, and radio shows are about relationships and tips on how to get the man of your dreams. For this article, I will analyze a chapter in his book "How to talk to man". This book provides women with different chapters that cover different situations and an explanation of what to do or what to say, and things women should not do. The chapter chosen for this analysis is about "how to charm him with your texts". It covers different scenarios and provides the reader with scripts to illustrate women on how to respond. However, Hussey

(C) Authors. Terms and conditions of Creative Commons Attribution 4.0 International (CC BY 4.0) apply. Correspondence: Valeria Márquez Arellano (MA student), University of Guanajuato, Division of Social Sciences and Humanities, Lascuráin de Retana No. 5, Colonia Centro, ZIP code 3600o, MEXICO. E-mail: valo.mrqz@gmail.com. 
categorizes women into four different types, and he presents chunks of conversations portraying women into these categories.

- Throughout his book, Matthew Hussey categorizes women in four different types that may affect the development of their identity.

- How women are categorized might be due to different ideologies, contexts, and cultures.

- Marketing strategies might be involved to target certain audiences.

\section{Theoretical framework}

To analyze this chapter, I decided to work with a critical discourse analysis (CDA) framework. CDA "typically examines a combination of linguistic features to discern how language functions in the reproduction of social structures" (Remlinger, 2008: 116). In addition to this, Fairclough (2010) explains that CDA is a "transdisciplinary analysis of relations between discourse and other elements of the social process" (p. 10). Therefore, I decided to work with this framework since it provided me with an insight to a combination of different features that can be examined in a discourse.

Additionally, the chapter which I analyzed for this study contains some discourse that seems to be categorizing women. Van Dijk (2010) discusses that critical discourse analysis is an interdisciplinary area that comments on the ethnography of communication as well as "other approaches to the social and cultural aspects of language use" (p. 8). As a result, one aim of critical discourse analysis is "exposing strategies that appear normal or neutral on the surface but which may in fact be ideological and seek to shape the representation of events and persons for particular needs" (Machin \& Mayr, 2012: 5). This study analyzes what is underneath the discourse that is presented, and it examines it from a different perspective. It takes into consideration some aspects such as gender, power, and ideologies, to mention a few.

Another area which informs this study is feminist critical discourse analysis. To begin with, Lazar (2007) discusses that:

The aim of feminist critical discourse studies, therefore, is to show up the complex, subtle, and sometimes not so subtle, ways in which frequently taken-for-granted gendered assumptions and hegemonic power relations are discursively produced, sustained, negotiated, and challenged in different contexts and communities (p. 142).

Because of this, feminist critical discourse analysis pays closer attention to gender, discrimination, and stereotypes, among others in both spoken and written discourse to draw upon some of the realities that women face. In addition to this, Lazar (2007) explains that feminist critical discourse is concerned with "the interrelationships of gender, power, and ideology in discourse" (p. 144). That is why it is important to comment on this to have another perspective on the chapter which was analyzed for this study. Also, to provide more information to the area of feminist critical discourse analysis.

\subsection{Gender and discourse}

First, it is important to define the term gender. According to Coates (2004) gender "is the term used to describe socially constructed categories based on sex" (p. 4). For this study, I will look at gender in terms of male and female. It is important to draw upon this to avoid any further type of discrimination. Gender, however, has changed according to the influence of cultures and how people see it, more specifically when it comes to the roles males and females have to follow. Remlinger (2008) explains that "gender roles are constituted through people's everyday lived 
experiences and influenced by cultural meanings" (p. 115). That is why according to each culture, the role that has to be followed. For instance, women belong to the kitchen, and men are the ones to provide money and food to the house; women should only perform certain jobs whereas men can work in places that require more strength, to mention some scenarios.

In the area of discourse, gender has a slightly different role. Halliday and Webster (2007) explain that when it comes to language and structures, we are concern about how typical the context of the situation, the function and the structure of the words are, we then see how language works as a form of behavior. However, the area of gender in discourse analyzes how women are to look according to what is exposed through media, texts, and/or spoken discourse, and sees how women are according to this ideal that is being portrayed (Cameron, 1992). In this case, this article pays closer attention to how women are portrayed and the roles they have to play to be accepted, or as the author claims, to get the man.

\subsubsection{Texting}

It is important to comment on texting for this study. The chapter to be discussed offers some advice on how to respond to certain texts. First, Halliday, Hasan and Christie (1989) highlight that "the way the text is interpreted in its context of situation" (p. 47). There are different scenarios discussed in the chapter, but the interpretation of it will vary according to different aspects such as the context, the reader, ideologies, and cultural background.

However, little is known concerning texting in the area of discourse analysis. There is more literature concerning written discourse rather than texting. Nowadays, texting has become part of the way humans communicate, and it opens up a different channel. Machin and Mayr (2012) mention that "language is not simply a vehicle of communication, or for persuasion, but a means of social construction and domination" (p. 24). In addition to this, how people reply to a text depends on what he or she seeks to aim, and thus "linguistic strategies are after all chosen within particular social contexts and relations" (Cameron, 1992: 71). In this study, Hussey provides women with different options to guide them in their written conversation, and thus the context and strategies are set up scenarios. Finally, Halliday (1994) comments that "language can effectively express ideational and interpersonal meanings only because it can create text" (p. 130). Therefore, I can look at the chapter and at the texts provided from different perspectives, whether is ideational, interpersonal, or from a feminist point of view.

\subsection{Feminism: What women think?}

Feminism has become an important area to conduct research. The emphasis and the attention to research in feminism do not only examine political or work ideologies, but it also covers it linguistically. First, "women can never be defined" (Minh-ha, 2005: 39). Women can be called different names or might be categorized, and Minh-ha explains how even with these names or categories women are all of them and still cannot be completely defined. Cameron (1992) depicts that:

there is also a good deal of feminist work emphasizing the importance of cultural representations of gender [...] in stories, pictures, textbooks, scholarly articles, and so on - in forming the identities of real women and men, their notions of masculinity and femininity, their expectations of what is possible and their ideas of what is normal (p. 5).

In other words, how women are categorized and/or represented may influence their identities and their ideas of what is right or not according to their culture or society. Lakoff (2005) describes how women have this unconscious script which has been the result of different 
ideologies that position women and their roles in a certain way. This is then the effect of women's language:

It submerges a woman's personal identity, by denying her the means of expressing herself strongly, on the one hand, and encouraging expressions that suggest triviality in subject matter and uncertainty about it; and, when a woman is being discussed, by treating her as an object - sexual or otherwise - but never a serious person with individual views (p. 243).

Yet, society and culture have shaped these ideas where women are to follow certain roles, converse on certain topics, and remain silent in others. It is important to consider whether the discourse provided in the chapter is part of what is considered women's language and if it creates some type of discrimination or stereotype which will be discussed in the following section.

\subsection{Discrimination or a stereotype}

I shall first define the concepts of discrimination and stereotype to understand what each term entails. According to the American Psychological Association (2016), discrimination refers to the "unfair or prejudicial treatment of people and groups based on characteristics such as race, gender, age or sexual orientation" (pp. 2). Ellemers (2018) explains how stereotypes "in general and gender stereotypes in particular may be helpful [...] when trying to understand how large groups of people generally differ from each other" (p. 278). On that account, discrimination is how people are treated based on different characteristics, and stereotypes can be seen as a way to distinguish or to label groups of people based on certain characteristics that might not be related to their race or gender.

To understand more how these terms inform the study, Fairclough (2010) provides with a discussion on a conversation where people may infer that women have certain tendencies, and thus it is explained that this representation of the language comes from an ideology where any given representation is linked to a particular social base. In addition to this, Fairclough (2010) defines ideational as:

naturalized implicit propositions of an ideological character are pervasive in discourse, contributing to the positioning of people as social subjects. These include not only aspects of ideational meaning [...] but also for instance assumptions about social relations underlying interactional practices [...] Such assumptions are quite generally naturalized, and people are generally unaware of them and of how they are subjected by/to them (p. 26).

Therefore, how Matthew Hussey positions women in his book might be the result of these different ideologies created by society. Also, how women are supposed to talk or to act changes depending on the context, the culture, and the norms proposed by such culture. Spender (2005) highlights the fact that naming is part of human nature, "names are essential for the construction of reality [...] By assigning names we impose a pattern and a meaning which allows us to manipulate the world" (p. 97). Then, the categorization Hussey provides might not be considered an act of discrimination or stereotyping, but a human act of giving names to target a specific audience. The following section includes the analysis of the chapter which draws upon the previously mentioned terms.

\section{Analysis of chapter}

Hussey begins his chapter by explaining the purposes of texting. Then, he introduces "Four Types of Women He Hates Texting (and What You Should Say Instead)". The following data contains the description of the four different types of women according to him: (1) The Court 
Jester; (2) The Tweenie Fangirl; (3) The Over-Analyzer, and (4) The Blank Wall. Moreover, Hussey provides women with different scripts that represent each type of woman, and in some cases, he includes the appropriate answers. Hussey's book also has a key for the colors used in the scripts at the beginning of his book. Red stands for what should not be said and green stands for the things that might be used instead.

\section{1 "The Court Jester"}

The first category in Hussey's chapter is “The Court Jester”. Hussey uses this category for women who tend to use jokes in what seems to be an extreme way. He explains:

This girl just can't stop joking... And not in a good way. Everything to her is an excuse to bust out another knee-slapper. Except she totally overdoes it. It's exhausting. She thinks it's raising her value. But in fact, the guy stops seeing her as a sexual possibility. She starts to seem like his goofy buddy.

In the previous excerpt, Hussey indicates that when a woman jokes excessively, she loses all her sexual possibilities. In this case, it is suggested that a woman's first approach to man is for a sexual purpose. It is important to highlight the fact that Hussey's book is about how to get the man, and thus some information regarding sexual intercourse is suggested throughout the book. The following script includes a negative example of "The Court Jester" type of women: E.g. Him: It was fun hanging out last night. Hope to do it again
soon! $(-)$

Her: Oh yea, it was awesome. Remember when I kicked your ass at $\mathrm{XBOX}$ ?

Him: Lol of course! You looked so cute in that shirt btw $x$

Her: Is this your way of changing the subject because you don't want to talk about it? :p

Image 1. Matthew Hussey's negative example of "The Court Jester"

Contrary to the previous script, here Hussey includes a script of what to say instead:

Him: It was fun hanging out last night. Hope to do it again soon! (-)

Her: I know, it was so nice! Except, I have to admit, I feel kind of

bad for beating you at $X B O X$.

Him: Lol it's ok, since you looked so cute in that shirt

Her: Well I had to make it up to you somehow;)

Image 2. Matthew Hussey's positive example of "The Court Jester"

The red script seems to portray women as 'rude' whereas the green script seems to label women as someone who has to make herself less than a man to be accepted. However, at the end of this section, Hussey highlights the fact men are also into women who have a "sense of humor", and thus advise women not to overdo it. Also, Hussey explains that depending on how close or familiar you are to him, the type of answers you should give to "keep the flirtation going". This first category positions women to be inferior and it seems to limit them in terms of the topics that can be exchanged in a conversation between man and woman (Lakoff, 2005). Yet, it should 
be noted that this first categorization is concerned with different ideas among cultures, and countries on how women might respond or act in front of or to men.

\section{2 "The Tweenie Fangirl"}

The second category in the book is "The Tweenie Fangirl”. This category is concerned with the overuse of emoticons/emojis in a conversation. Hussey depicts the following:

This one has the cutesy, air-headed nature of a sixteen-year-old commenting on

YouTube, and peppers every text with a thousand emojis, because apparently words aren't enough to express how she feels.

First, Hussey compares women who overuse emojis as if they were teenagers. He also implies that the use of emojis is the result of not knowing how to fully express in a conversation. Yet, it is important to comment that people, regardless of their age, nowadays use more emojis to illustrate their ideas as texting has evolved during the past years. The following is an example of this category to illustrate his idea:

E.g. "OMFG just ate dis amzing bagel in a bakery near yr plce. $U$

hav to try it smetime! LOL :p (-) Xox"

Image 3. Matthew Hussey's negative example of "The Tweenie Fangirl"

After Hussey includes the previous script, he also comments on the overuse of abbreviations as if it were something negative. Again, texting has evolved and become a more frequent channel of communication. However, Hussey then explains that this overuse of emojis and abbreviation might reflect on the intelligence of the person:

It's unnecessary and causes guys to make snap judgments about your intelligence. In texting, all you have are the words you write on which to be judged. When he reads messages in what looks like a sixteen-year-old teenager's language, he's going to assume you have the mind of one [...] Any successful guy who reads text speak like this will be fearful of introducing you to his more respectable friends.

Again, Hussey includes discourse that seems to make women inferior. Hussey explains how depending on the type of (written) discourse used in the conversation, whether a man will introduce you to his friends or not. This category draws upon Cameron (1992) and Lakoff's (2005) ideas of how women are represented and how these categorizations can have an effect on the identity of women, especially teenagers that have access to his book.

\section{3 "The Over-Analyzer"}

In my opinion, the following category illustrates a woman who might be considered to be independent in this era. Hussey describes "The Over-Analyzer" as:

This girl overthinks everything. She tries to have an oh-so-clever comeback for everything a guy says. She is always in her head, and can't let anything go.

The way Hussey describes an over-analyzer seems to infer that a woman cannot have a much clever answer than a man, and thus positions women as submissive again. The following script shows an example of this: 
Him: Still thinking about you in that red dress you tried on today.

I know this sounds weird, but it makes your shoulders look really

$\operatorname{sexy} \ldots x$

Her: What? Are you saying I have big shoulders?

Him: No! Im saying they're hot.

Her: Hmmm ok lol

Image 4. Matthew Hussey's negative example of "The Over-Analyzer"

In contrast to Hussey's description of the over-analyzer, the previous script includes a conversation where a man compliments a woman, and she does not accept it but instead seems to be offended. First, the script and the definition of the over-analyzer do not coincide since the definition implies that women cannot have a much clever answer than men, but then provides an example where women cannot accept a compliment. Moreover, the following excerpt complements his idea and script:

The over-analyzer can't help but dissect everything a guy says until he's completely drained and exhausted. This is the opposite of confident communication.

The previous excerpt shows a description that coincides more with the script used in this categorization. Hussey explains that to have more "confident communication" women have to acknowledge the compliment, and compliment men as well. In this case, I agree with the idea that it is important to acknowledge a compliment regardless of the person who says it. However, how Hussey represents an "over-analyzer" in this section does not completely coincide in all his examples and what can be inferred with that label.

\section{4 "The Blank Wall"}

The last category offered in the chapter is "The Blank Wall". Here, Hussey defines it as women who do not get involved in the conversation or who do not formulate enough to have longer conversations.

The Blank Wall gives you nothing to go on, just simple, lame responses that give him no material to work with.

This excerpt, however, also highlights that this vague content does not provide him with information to have follow-up conversations. In this case, it can be inferred that women are expected to include useful or interesting information, and thus the conversation will flow. The following script depicts that:

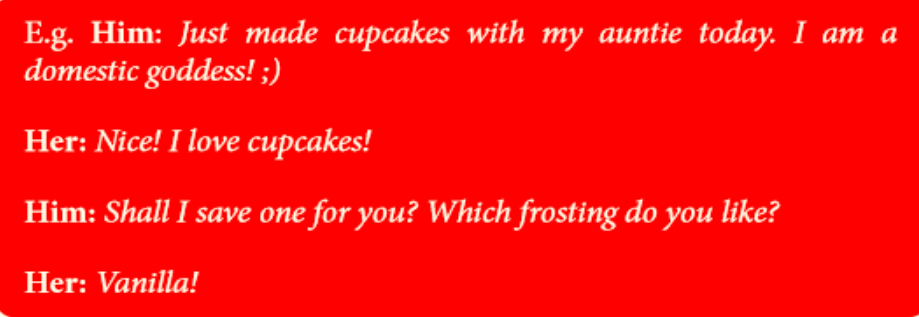

Image 5. Matthew Hussey's negative example of “The Blank Wall”

Yet, texting depends on two people (in this case) to make the conversation flow, not only depends on one person. Hussey then infers that the use of "lame responses" might indicate a 
lack of interest whereas Halliday, Hasan, and Christie (1989) explain that how a text is interpreted might be due to the context or the situation. Hussey then includes the following:

After three or four of these texts, a guy will simply assume you're either not interested or you have nothing to say and that you're dull. He's doing the heavy lifting and getting bland, dull responses in return.

In this case, it should not be expected for neither men nor women to always provide longer responses to continue with the conversation. There might be more things happening at the time of texting which interfere with the flow of the conversation such as their jobs, schools, chores, to mention a few. Thus, it should not be inferred that these "lame responses" indicate a lack of interest from neither of them. Then Hussey suggests the following type of responses:

Him: Just made cupcakes with my auntie today. I am a domestic goddess! ;)

Her: Oh, you never make me cupcakes, I don't know whether to be angry or hurt.

Him: Shall I save one for you? Which frosting do you like?

Her: I like Vanilla, but it better come with a smiley face, a heart, or a sexy kiss. Your choice.

Image 6. Matthew Hussey's positive example of "The Blank Wall”

Hussey here provided an example that included more flirting between man and woman. It again has a sexual connotation that Hussey explains will eventually create a connection. However, the example portrays men in a different role "the domestic goddess" which shows how men can also be part of tasks that are normally considered for women.

\section{Conclusion}

To sum up, Hussey's chapter provides women with advice on how to respond to men and categorizes them at the same time. This article focuses on how women are described from feminist ideology. To some extent, some of the categorizations provided in the article portray an inferior or submissive stereotype of women who need to follow certain scripts to "get the man". This article also explained how certain roles and ideologies are involved in each category: women should avoid certain topics; women are less intelligent when overusing certain things in a conversation; women should portray themselves as inferior to men, to mention a few. Yet, it is important to remember that the goal of Hussey's book is to help women to get the man. Therefore, the categorizations used in this chapter might not indicate a type of discrimination, but a marketing strategy to target certain people whose relations might not succeed due to specific patterns or "mistakes" they make. Finally, this article sheds light on how culture, context, and ideologies may influence the way a woman should behave and how this may also have an effect on their identity.

\section{Acknowledgements}

I would like to thank my friends, my family, and my students for their support and for being there. Pamela Galindo, this would not have happened if it were not for you. Also, I would like to thank my professor, Dr. Troy Crawford Lewis for his guidance and encouragement to conduct this research. 
This research did not receive any specific grant from funding agencies in the public commercial, or not-for-profit sectors.

The authors declare no competing interests.

\section{References}

American Psychological Association (2016). Discrimination: What it is, and how to cope. http://www.apa.org/helpcenter/discrimination.

Cameron, D. (1992). Feminism and linguistic theory. Macmillan.

Coates, J. (2004). Women, men and language: A sociolinguistic account of gender differences in language (3rd ed.). Routledge.

Ellemers, N. (2018). Gender stereotypes. Annual Review of Psychology, 69, 275-298. https://doi.org/10.1146/annurev-psych-122216-011719

Fairclough, N. (2010). Critical discourse analysis: The critical study of language ( $2^{\text {nd }}$ ed.). Routledge.

Halliday, M. A. K. (1994). Language as social semiotic: The social interpretation of language and meaning. Edward Arnold.

Halliday, M. A. K., \& Webster, J. (2007). Language and society. Continuum.

Halliday, M. A. K., Hasan, R., \& Christie, F. (1989). Language, context, and text: Aspects of language in a social-semiotic perspective. Oxford University Press.

Hussey, M. (n.d.). How to charm him with your texts. In How to talk to men: Fifty-nine secrets scripts to melt his heart, unlock what he's thinking, and make him want to be with you forever. From https://www.howtogettheguy.com/

Lakoff, R. (2005). Extract from language and woman's place. In D. Cameron, The feminist critique of language: A reader ( $2^{\text {nd }}$ ed.). Routledge.

Lazar, M. M. (2007) Feminist critical discourse analysis: Articulating a feminist discourse praxis. Critical Discourse Studies, 4(2), 141-164. http://dx.doi.org/10.1080/17405900701464816

Machin, D., \& Mayr, A. (2012). How to do critical discourse analysis: A multimodal approach. Sage.

Minh-ha, T. T. (2005). Difference: A special third world women's issue. In D. Cameron (Ed.), The feminist critique of language: A reader ( $2^{\text {nd }}$ ed.). Routledge.

Remlinger, K. A. (2008). Negotiating the classroom floor: negotiating ideologies of gender and sexuality. In M. M. Lazar, Feminist critical discourse analysis: Gender, power and ideology in discourse. Palgrave Macmillan.

Spender, D. (2005). Extracts from manmade language. In D. Cameron (Ed.), The feminist critique of language: A reader ( $2^{\text {nd }}$ ed.). Routledge.

Van Dijk, T. A. (2010). Discourse and context: A sociocognitive approach. Cambridge University Press. 
V. Márquez Arellano - Do not Tell me How to Talk to Men! A Critical Discourse Analysis...

C O A $\mathrm{s}$ 